\title{
Electrolyte Replacement Preparation
}

National Cancer Institute

\section{Source}

National Cancer Institute. Electrolyte Replacement Preparation. NCI Thesaurus. Code C29638.

A mixture containing electrolytes used to prevent or treat electrolyte imbalance that can be caused by abnormal levels of sodium, magnesium, phosphate, chloride, bicarbonate and/or potassium. Severe electrolyte disturbances can cause cardiac and neurological problems, organ failure and eventually death. 